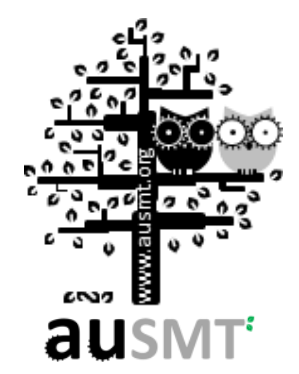

\title{
Developing an Engineering Data Bank Service for the Precision Machinery Industry Cluster Using the Living Lab Concept
}

Kuo-Shu Luo, Shiang-Shin Lin, Kuei-Kai Shao*, and Hui-Hua Lin Industrial Technology Research Institute, Taiwan (Received 1 March 2012; Accepted 18 June 2012; Published on line 1 September 2012)

*Corresponding author: davidshao@itri.org.tw DOI: $10.5875 / a u s m t . v 2 i 3.147$

\begin{abstract}
In Taiwan the precision machinery industry has always played an important role in promoting important industrial upgrades. Small and medium enterprises (SMEs) account for the vast majority of participants in this industry. Because of their size and number they face a number of problems. These include difficulty in responding quickly to market demand, a low level of collaboration, and insufficient interaction between designers in central factories and the subcontractors who manufacture components for them. Taiwan's i236 initiative applied a Living Lab Concept, along with information and communication technology (ICT), to develop a cloud-based 'Engineering Data Bank Service' to act as a hub for gathering data together from a local precision machinery industry ecosystem. The Taichung City Precision Machinery Innovation Technology Park was selected as the test site. After deploying the service to more than 400 SMEs, it is found that this service has a low deployment cost, and can indeed effectively enhance the working efficiency of R\&D personnel and increase the interaction between central factories and subcontractors, thereby enhancing the international competitiveness of the precision machinery industry in Taiwan.
\end{abstract}

Keywords: Engineering Data Bank; Information and Communication Technology (ICT); Living Lab Concept

\section{Background}

In Taiwan the precision machinery industry has always played an important role in promoting important industrial upgrades. In 2010 Taiwan was the fifth largest production country and the fourth largest exporting country for precision machinery. According to the Taiwan Association of Machinery Industry (TAMI), the output value of the precision machinery industry in 2011 is not only more than the output value in 2010, but also exceeds the output value of Italy, becoming the third largest exporting country of machine tools. Nowadays, in order to enhance international competitiveness, the machine tool industry has to respond with a low cost and high performance policy. Besides lowering production costs by enhancing manufacturing technology and modularizing components, the industry has to develop localized and low cost key technologies and key components for itself. These would include high speed spindles, high speed feeding, precision ball bearings, high speed and high precision ball screws, high performance servo motors, servo controls, and CNC software, etc. Therefore, the development and design of key technologies and key components is an important goal for the future development of the machine tool industry [1]. 
The Precision machinery industry covers an extremely wide range of enterprises, not just a single industry or a particular technology. Besides devoting themselves to enhancing their technology capabilities, companies in this industry also have to consolidate their intellectual property protection, and the management of cross-supply-chain information transmission, etc., to achieve the goal of becoming the third highest producer of precision machine tools and another trillion-dollar industry. The present status of the precision machinery industrial development is described as follows [2, 3]:

- After the Economic Cooperation Framework Agreement (ECFA) was negotiated successfully hundreds of producers of machinery products listed in the Early Harvest List have benefited. When interviewed by the Commercial Times, Mr. Hsiu Tsang Hsu, Chairman of TAMI, pointed out that the boom of 2012 is conservative but optimistic, and the growth rate should be at least $8 \%$; and it is forecast that the output value of the machinery industry will have the chance to break 33.3 billion USD in 2012 or 2013.

- The market in Mainland China provides great opportunities for the machine tool industry in

Kuo-Shu Luo is project manager of the Service System Development Division, Service System Technology Center, Industrial Technology Research Institute, responsible for the development and management of software related to precision machinery and smart tourism. He is one of the consulting team which helped Taichung City to win "The Top Seven Intelligent Community of the Year 2012" award with the Engineering Data Bank Service. The current research interests of Mr. Luo are eTourism, and Smart Agnet Communications. Mr. Luo received a B.S. in Industrial and Systems Engineering from Chung Yuan Christian University and a M.S. in Industrial Management from National Central University.

Shiang-Shin Lin is an engineer with the Service System Development Division, Service System Technology Center, Industrial Technology Research Institute. He is one of the consulting team which helped Taichung City to win "The Top Seven Intelligent Community of the Year 2012" award. Prior to joining the i236 program, Dr. Lin participated in the Satellite Program, the Aviation project, the Industrial Cooperation Program, and a RFID promotion project. Dr. Lin received a B.S. in Mechanical Engineering from National Taiwan University, an M.S. in Mechanical Engineering from the University of Massachusetts, and a Ph.D in Engineering Science and Mechanics from Virginia Polytechnic Institute and State University

Kuei-Kai Shao received an M.S. in Industrial Engineering and Management from National Taipei University of Technology, and is currently working at the Industrial Technology Research Institute as a project manager for the multifunctional Taichung Intelligent Industrial Park (i-Park), which is part of the $i 236$ project, mainly utilizing ICT-Embedded Innovation services, and Engineering Data Bank services. The purpose of this project is to provide value-added services to small and medium enterprises in the precision machinery industry. This project helped Taichung City to win "The Top Seven Intelligent Community of the Year 2012" award. Mr. Shao has also implemented a Processed Food Tracking project using RFID/QR-Code technology to assist food producers, logistics providers, and retailers to construct complete food pedigrees from farm to table.

Hui-Hua Lin graduated from Oklahoma City University. Ms. Lin was an employee of the Service System Development Division of the Service System Technology Center, Industrial Technology Research Institute. She was mainly responsible for the marketing and planning of the multifunctional Taichung Intelligent Industrial Park (i-Park) as part of the i236 project.
Taiwan. The GDP of Mainland China in 2012 should be around $8 \%$, and the machine tools imported from Taiwan to Mainland China within the first 11 months in 2011 increased 45\% compared to the amount imported in 2010. However, a 65\% increase from Japan and a $57 \%$ increase from Germany indicates that the market demand is pretty strong. Therefore, the machinery industry in Taiwan has to enhance its competitiveness and strive for tax reductions and exemptions within the ECFA as soon as possible.

- $\quad$ The FTA signed by South Korea with the EU and the United States has had a great impact on the export market of the machinery industry from Taiwan to Europe and the United States. The value of all exports from Taiwan to the United States is 4-5 billion USD annually and 800 million USD of this export value is from machine tools. Taiwan's exports to Europe and to the United States must yield a profit of $2-5 \%$ just to meet tariff margins. On the other hand, South Korea's machinery equipment is entitled to access to European and American markets free of duty. During this extraordinary period, the government of Taiwan needs to take some special measures to help the machinery industry by expanding the subsidy for exhibiting and exploring markets in Europe and the United States.

Small and medium enterprises (SMEs) account for the vast majority enterprises in Taiwan's precision machinery industry. According to the 2010 Machinery Industry Yearbook [4], most SMEs face the following problems:

1. They are small scale, have weak R\&D capability, and low R\&D budgets.

2. Domestic machine tool production is only a small part of the domestic market and so local companies have to rely heavily on imported components.

3. SME's in the precision machinery industry pay relatively low salaries, and find it difficult to retain talent.

4. Products, materials, processes, and key processing technologies for components cannot be effectively integrated.

5. The precision machinery industry as a whole is unable to quickly respond to market demand, resulting in long design time delays.

6. There is insufficient interaction between designers in central factories and the subcontractors who manufacture components for them.

7. Development time is lengthy and low levels of collaboration reduce production efficiency. 
By introducing ICT it should be possible to assist the precision machinery industry to solve the aforementioned problems. However, the "2010 Machinery Industry Yearbook" [4] shows that manufacturers located in the Taichung Industrial Park, the Tachia Youshih Industrial Park, the Dali Industrial Park the Taichung Precision Machinery Park, and the Taipin Industrial Park are generally small in scale, and, because of their small size, provide only limited human and financial investment in ICT technology. It is found that the possible causes why Taiwan's machinery industry has not yet introduced ICT include [5]:

1. Most of the factories are too small, and think that introducing ICT will result in administrative burdens and inefficiencies.

2. The cost of purchasing or developing professional software is too expensive for the SMEs to afford, which reduces deployment willingness.

3. It is hard for internal employees to accept the changes in operational processes and methods which would be necessary when ICT is implemented.

4. The Machinery industry has a shortage of qualified ICT personnel.

Wikimedia describes a "living lab" this way: "A living $l a b$ is a research concept. A living lab is a user-centered, open-innovation ecosystem, often operating in a territorial context (e.g. city, agglomeration, region), integrating concurrent research and innovation processes within a public-private-people partnership.

The concept is based on a systematic user co-creation approach integrating research and innovation processes. These are integrated through the co-creation, exploration, experimentation and evaluation of innovative ideas, scenarios, concepts and related technological artifacts in real life use cases. Such use cases involve user communities, not only as observed subjects but also as a source of creation. This approach allows all involved stakeholders to concurrently consider both the global performance of a product or service and its potential adoption by users. This consideration may be made at the earlier stage of research and development and through all elements of the product life-cycle, from design up to recycling. [6]

In recent years the Taiwan government has begun to implement a Smart Living Technology Program (i236), in order to encourage existing technologies to collaborate in the development of smart living applications. The Taichung Precision Machinery Park was selected as a specific test site and carrier for implementing the intelligent park (i-Park) concept, which involves applying a living lab concept to upgrade traditional industry and to establish smart living application services by using an ICT infrastructure. The aim is to make it possible for domestic companies to carry out their commercial operations more efficiently and cost effectively within a smart living service environment.

\section{Intelligent Park and Services}

The great Taichung area is the densest precision machinery industrial cluster in the world, where more than 10 thousand companies contribute to the supply chain. These companies face a number of problems including insufficient integration between sales, design, and the production process; an inability to respond quickly to changes in market demand, and a lack of collaboration which results in inefficiency and long R\&D and design times.

This section describes how the Taichung City Precision Machinery Innovation Technology Park was selected to be the test site for an i-park, and how the project team from the Industrial Technology Research Institute (ITRI) developed ICT-enabled Engineering Data Bank services by applying the Living Lab Concept to solve the problems stated in the background section.

\section{The Development of an Intelligent Park (i-Park)}

The objective of establishing an i-Park is to actualize the concept of an industrial cluster, to enhance industrial and commercial efficiency, and to build up a safe and secure, comfortable and convenient working environment, thereby enhancing the international competitiveness of a traditional domestic industry. How to select a suitable i-Park test site from 228 industrial parks in the country became a very important question to answer. The development process of the i-Park is shown in Figure 1.

As seen in Figure 1, the development process of the i-Park can be divided into 3 stages: "site selection", "site architecture development", and "site establishment, development, and promotion, operation and transfer". While numerous sites were considered, only one site selection for executing the i236 program will be described. 


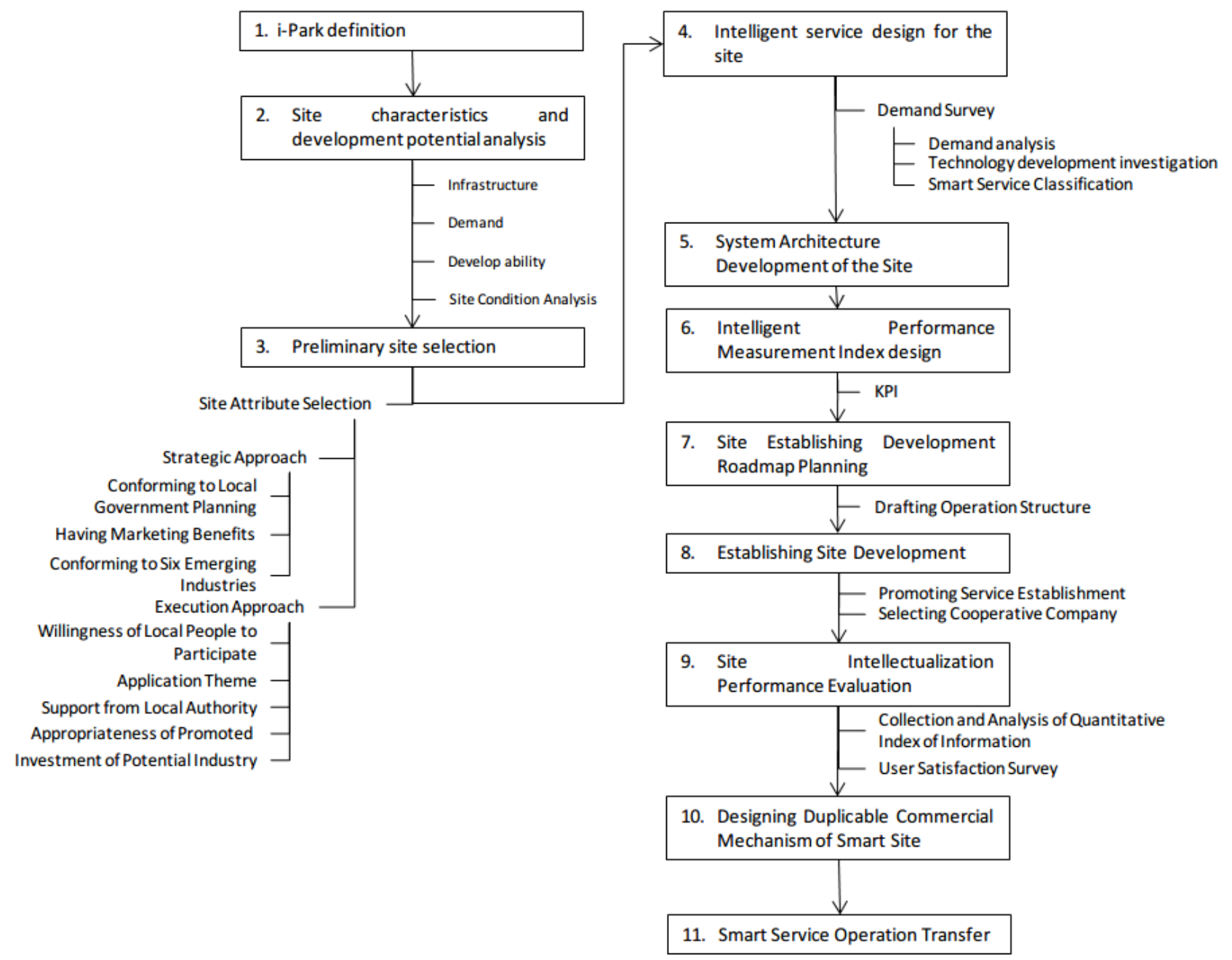

Figure 1. I-Park development flow chart.

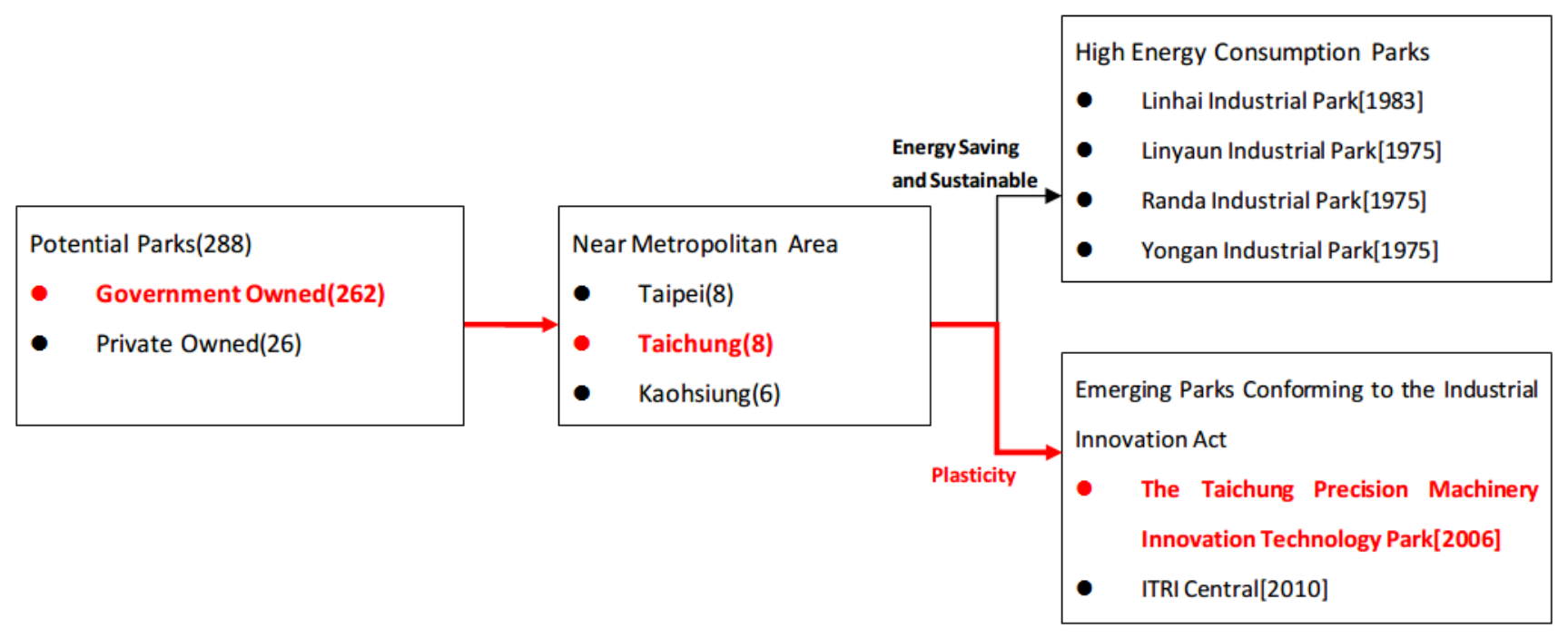

Figure 2. i-Park selection step. 


\section{Site selection process}

The stages during the process of selecting the i-Park site are as follows:

1. i-Park definition: An i-Park is an innovative model which creates a smart living site based on user-driven innovations, aiming to integrate novel technologies into current practice, to seek out new innovative applications, and to dig out innovative service and business models there from.

2. Site characteristics and development potential analysis: In this stage, the domestic industrial parks are roughly classified into the following three categories according to their site characteristics:

a. High energy-consumption parks: Parks mainly designed for heavy industry, heavy machinery processing, petrochemical industry, etc. like Linhai, Linyaun, Yongan, and Randa industrial parks, etc.

b. Emerging parks: Parks for particular industrial clusters, like Taichung City Precision Machinery Innovation Technology Park, Southern Taiwan Innovation \& Research Park, Chiayi Industry Innovation and Research Center, etc.

c. R \& D type parks: Highly knowledge-intensive parks like Nangang Business Park, Neihu Technology Park, Hsinchu Science Park, etc.

Seven additional indices, including R\&D intensity, policy matching, stage of development, access to an international port, nature of the industrial cluster, and the level of involvement of academic institutions and research institutions are also used as the basis for further analysis.

3. Preliminary site selection: the selection of a preliminary site is carried out based upon the attributes of the site, for instance, assessing the advantages of a high energy-consumption park versus an emerging park. The final selection of a park is based both on strategic factors and factors related to pragmatic implementation.

4. Smart service design for the site: After the site is preliminarily selected, a demand survey, a demand analysis, and a technology development investigation are performed to design a smart service to match the characteristics of the site.

\section{i-Park selection of the i236 program}

The i-Park selection process of the i236 program focuses on strengthening relative industrial and commercial activities. The actual selection is divided into the following three steps shown in Figure 2:

1. Twenty-two parks with international connections situated in or near metropolitan areas with access to international ports were preliminarily selected from a list of 228 domestic parks under consideration.

2. Four high energy consumption parks and two emerging parks which passed the first step according to their characteristics were selected.

3. The flexibility and plasticity of a park will determine the degree to which ICT enabled services can be implemented. For this reason the Taichung City Precision Machinery Innovation Technology Park, an emerging park conforming to the Industrial Innovation Act, was selected from six parks as the target i-Park

\section{i-Park working phases}

After a site is selected, the development of the site architecture, the establishment of the site and site development, promotion, and site operation and transfer follow. The operational process of carrying out these working phases can be described as shown in Figure 3.

The process of carrying out i-Park working phases starts with basic site information collection and closes with the execution of business transfers or exit actions if services are not applicable. The definitions for each process item are shown in Table 1.

\section{ICT-enabled Solution-Engineering Data Bank Service}

Since the machinery industry faces many problems as described in the background section, which need to be solved in order to enhance the industry's competitiveness, the execution team developed a cloud-based collaborative operation management service named the 'Engineering Data Bank' which was released for the companies in the new i-Park: the Taichung City Precision Machinery Innovation Technology Park.

The 'Engineering Data Bank Service' is an ICT-enabled service following the Living Lab Concept. The development was carried out by using Cloud-based operation and virtualization technology and SOA architecture, and driven by software value-added innovation services. The service had to be constantly and repeatedly tested to satisfy the true and necessary needs of the users. Furthermore, this service had to have a low deployment cost, had to be user-friendly, and needed to be maintenance free. 


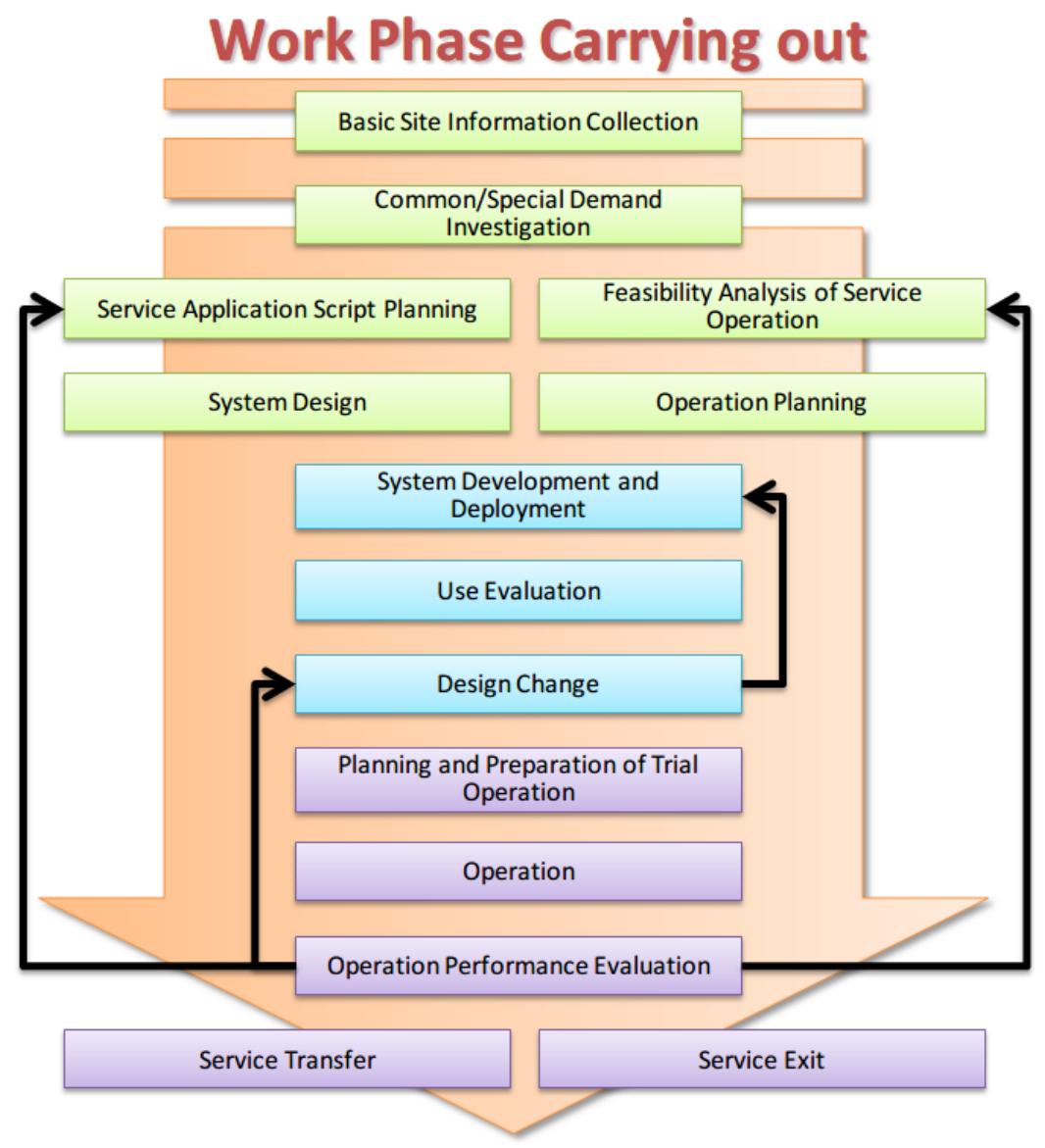

Figure 3. i-Park working phase flow chart.

Table 1. Definition of process items for carrying out i-Park working phases.

\begin{tabular}{|c|c|}
\hline Process Items & Definition \\
\hline $\begin{array}{l}\text { Basic Site Information } \\
\text { Collection }\end{array}$ & $\begin{array}{l}\text { Collecting city government investment items within a 2-5 year span and future } \\
\text { development roadmaps; Collecting company lists, production types, industrial } \\
\text { characteristics of the selected site }\end{array}$ \\
\hline $\begin{array}{l}\text { Common/Special Demand } \\
\text { Investigation }\end{array}$ & $\begin{array}{l}\text { Common Type: Service demands applicable to all the companies in the site. } \\
\text { Special type: Service demands only applicable to particular companies } \\
\text { Collecting demands by interview or forum }\end{array}$ \\
\hline $\begin{array}{l}\text { Service Application Script } \\
\text { Planning }\end{array}$ & $\begin{array}{l}\text { According to actual demand, planning application scripts and use scenarios of profitable } \\
\text { operations }\end{array}$ \\
\hline $\begin{array}{l}\text { Feasibility Analysis of } \\
\text { Service Operation }\end{array}$ & $\begin{array}{l}\text { According to the application scripts and scenarios, evaluating the user acceptance and } \\
\text { profit models }\end{array}$ \\
\hline System Design & $\begin{array}{l}\text { According to the application script and situations, expanding the system functions, } \\
\text { processes, and hardware and software architecture }\end{array}$ \\
\hline Operation Planning & Planning a business model for the application scenario \\
\hline $\begin{array}{l}\text { System Development and } \\
\text { Deployment }\end{array}$ & $\begin{array}{l}\text { According to system function expansion, performing system development and } \\
\text { deployment operations }\end{array}$ \\
\hline Use Evaluation & Evaluating system function applicability by site companies (users) \\
\hline Design Change & According to evaluation results, update system design functions \\
\hline $\begin{array}{l}\text { Planning and Preparation } \\
\text { of Trial Operation }\end{array}$ & $\begin{array}{l}\text { For the applicable system, performing operation launch planning and deployment } \\
\text { preparations }\end{array}$ \\
\hline Operation & Formally launching and operating system \\
\hline $\begin{array}{l}\text { Operation Performance } \\
\text { Evaluation }\end{array}$ & $\begin{array}{l}\text { Evaluating the actual performance system of system deployment to check whether it is } \\
\text { consistent with an intellectualization performance measurement index }\end{array}$ \\
\hline Service Transfer & Services are transferred to the leading manufacturers to carry out normal operations \\
\hline Service Exit & $\begin{array}{l}\text { Withdrawing inappropriate services through the exit process and carrying out review } \\
\text { operation planning }\end{array}$ \\
\hline
\end{tabular}




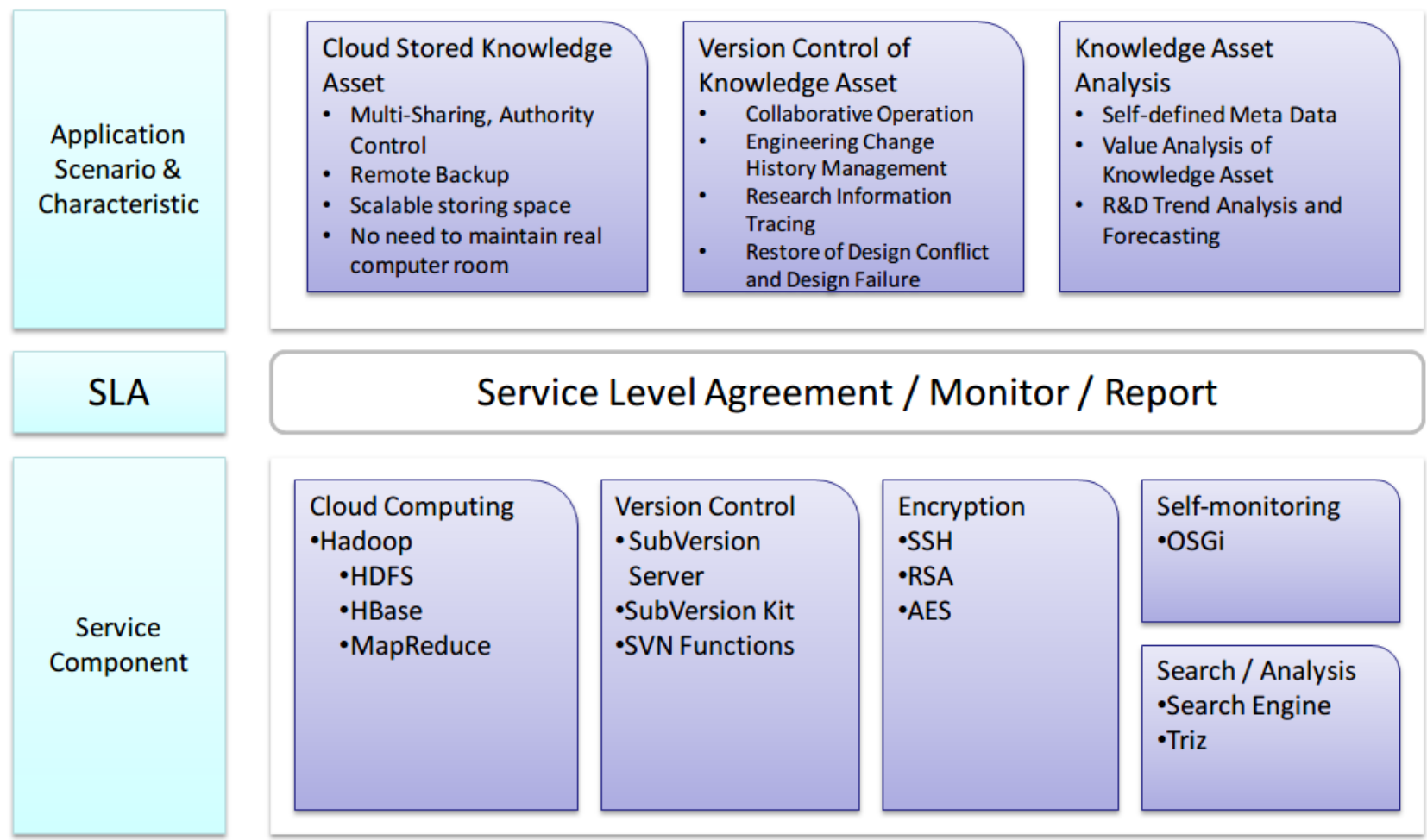

Figure 4. Architecture of Engineering Data Bank service.

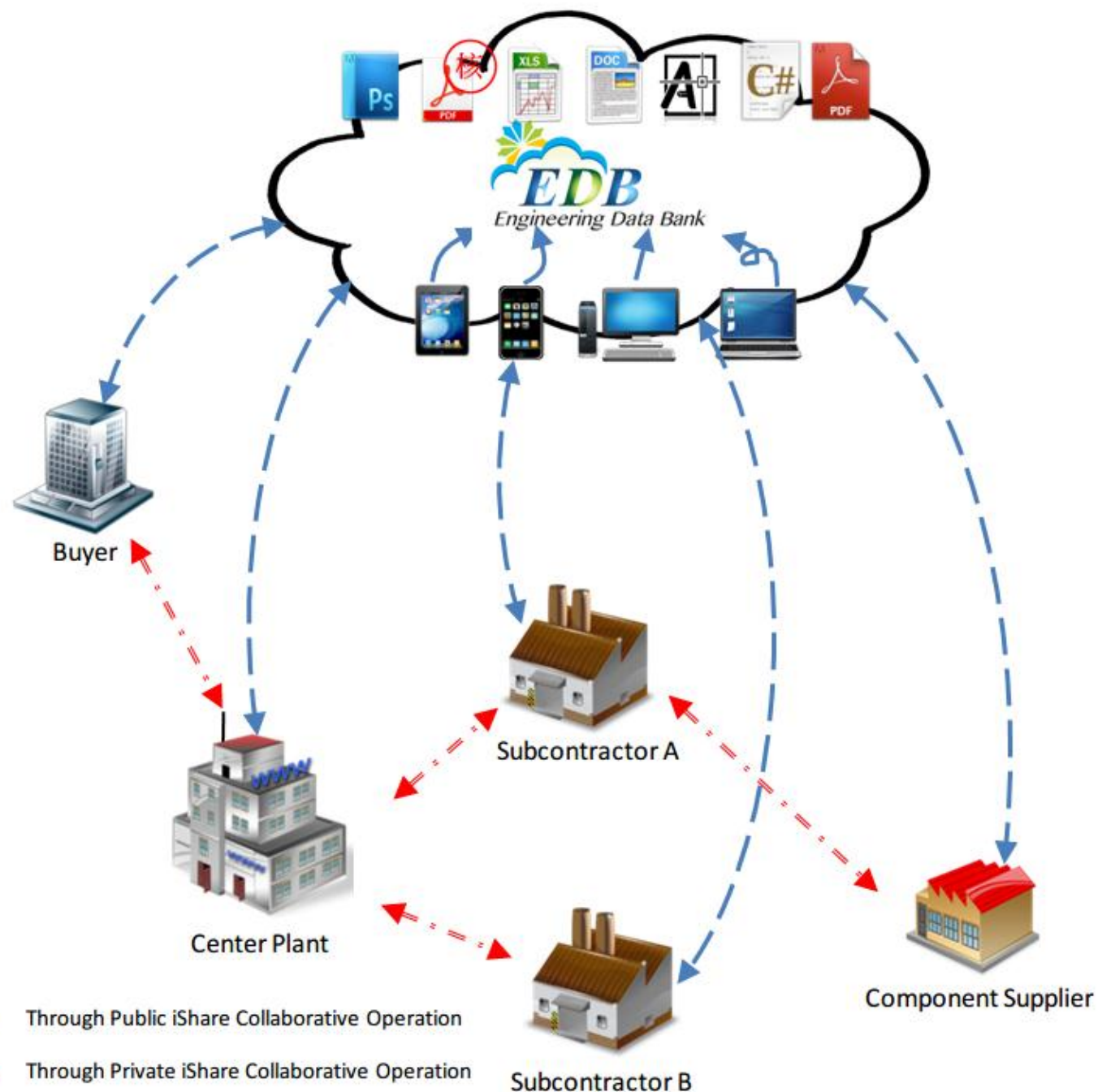

Figure 5. Cross-supply-chain integration manner of Engineering Data Bank service. 


\section{Architecture}

The systematic architecture of an Engineering Data Bank mainly comprises Application Scenarios \& Characteristics, Service Level Agreements (SLA), and Service Components. An Engineering Data Bank will provide different application scenarios and functions depending upon the SLA signed by the users. The architecture is shown in Figure 4.

\section{Operation model}

An Engineering Data Bank service is used to provide solutions for the users to select in a service-based manner. The spirit thereof should be the service instead of the product, i.e., the product is just a part of the service provided. The goal of developing an Engineering Data Bank Service is to provide a service platform with a low cost of deployment, fast data sharing, effective group communication, and collaborative operation, which integrates with the domain knowledge bases of SMEs in the precision machinery industry. The aim is to strengthen the capability of SMEs to protect their intellectual assets, to improve the management of information transmission within supply chains, etc. The service operation model is shown in Figure 5.

Important intellectual assets like engineering design drawings and research and development documents are always treated as protected assets by SMEs, most of whom have doubts about the security of documents stored in sites outside of the company. The cloud service platforms operated by ITRI or by other information service companies are all distrusted. The Engineering Data Bank Services described in Figure 5 are unique because they have the characteristics of a public cloud, but are in actual practice, private. The service can be transferred to internal SME locations to reduce worries about storage security for important intellectual assets and thus increase the acceptability of this service. Furthermore, through function differentiation, this service allows SMEs to freely select a suitable version fitting their own needs, so as to reduce the deployment cost of the service.

By adopting the technologies of high server availability, multi-tenancy, and load balancing, the service stability and scalability of the Engineering Data Bank service can be improved. The technologies adopted are shown in Figure 6.

This article focuses on illustrating how use of the Living Lab Concept can assist SMEs in Taiwan to enhance their operating efficiency and to strengthen their competitiveness, so the Engineering Data Bank service system itself is not described in detail.

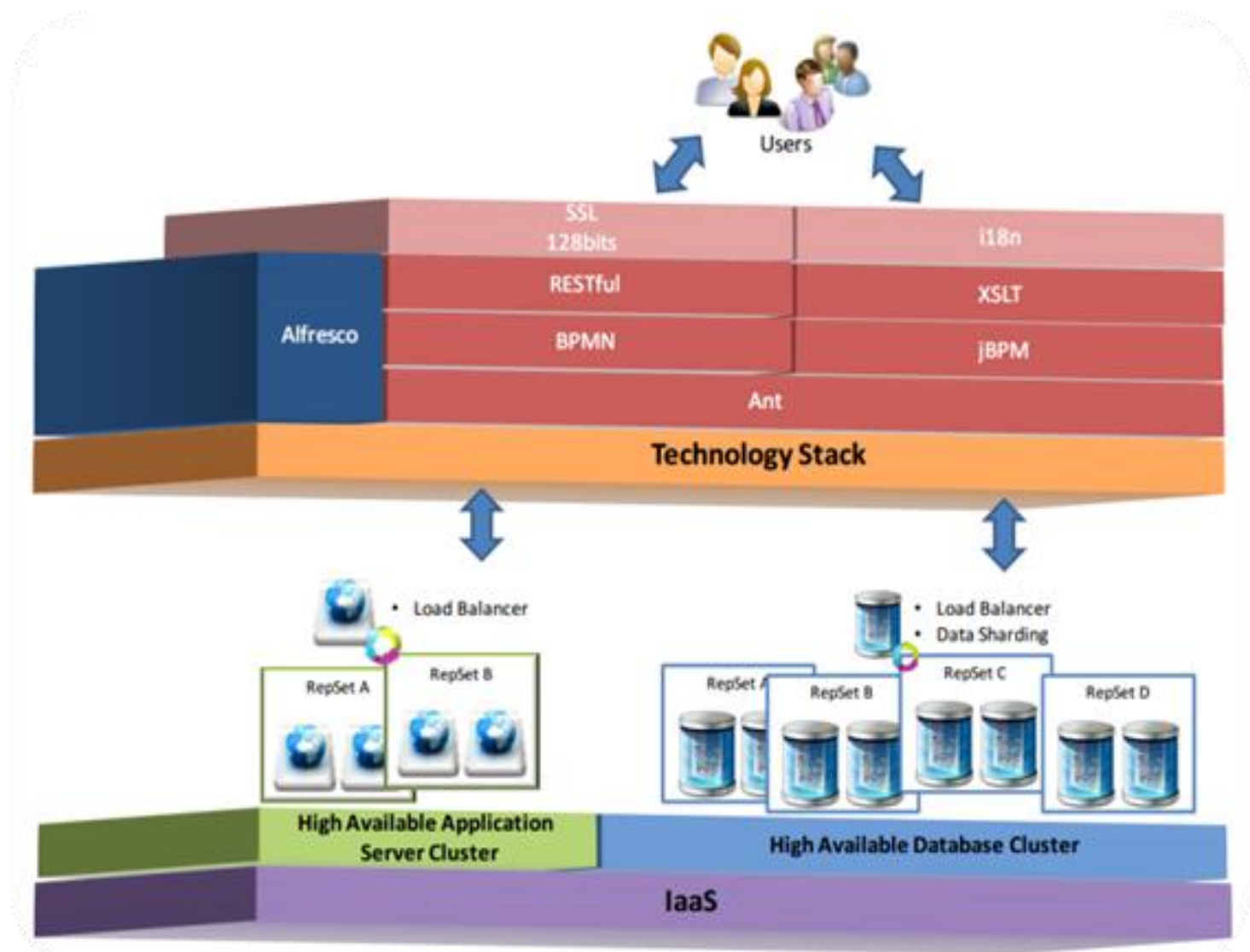

Figure 6. Description of adopted technology of Engineering Data Bank service. 


\section{Implementation}

This section will explain the process of how to establish the Ecosystem, how to decide the functions which need to be developed through the SIG model, and how to successfully increase the number of companies using the service to 400 .

\section{$i$-Park ecosystem}

Based upon many years of accumulated project execution experience, the program team used ITRI as an impartial third party for the important role of constructing the i-Park Ecosystem. This involved effectively integrating resources, gathering and integrating target customers, and engaging the public sector, academia, and industry to each play their own roles. The architecture of an i-Park Ecosystem, using the Engineering Data Bank as an example, is show in Figure 7.

Regarding the Ecosystem of the Engineering Data Bank, the project team effectively integrated the resources of all the parties involved, enabling all role-players to have a clearly defined position and function. These are briefly described as follows:

- Industry: Associations like the Precision Machinery Development Association of R.O.C., the Taiwan Machine Tool \& Accessory Builders' Association, the Tai Chung Computer Association, the Association of Global Development, etc., all played the role of industrial expert consultant and promoter of the service; the domestic IT service companies played the role of technology solution providers; and business partners played the role of service operators.

- Academics: The role played by academics in the Ecosystem was mainly to provide technology R \& D support and to conduct industry analysis research.

- Public sectors: The Taichung City Government played both the role of smart city consultancy recipient and of local government at the same time in the Ecosystem. The subordinate agencies in the Taichung City Government who participated in this project were the Research, Development and Evaluation Commission and the Economic Development Bureau. The Department of Industrial Technology of the Ministry of Economic Affairs (MoEA), was the guiding agency in this project. The Small and Medium Enterprise Administration of the MoEA was the cooperating agency.

- Target customers: The target customers of this project were manufacturers of the precision machinery industry, mainly playing the role of responding to industry demand, accepting the deployment of innovative smart services, and providing feedback on the results, data, and the experience of deployment in the Ecosystem.

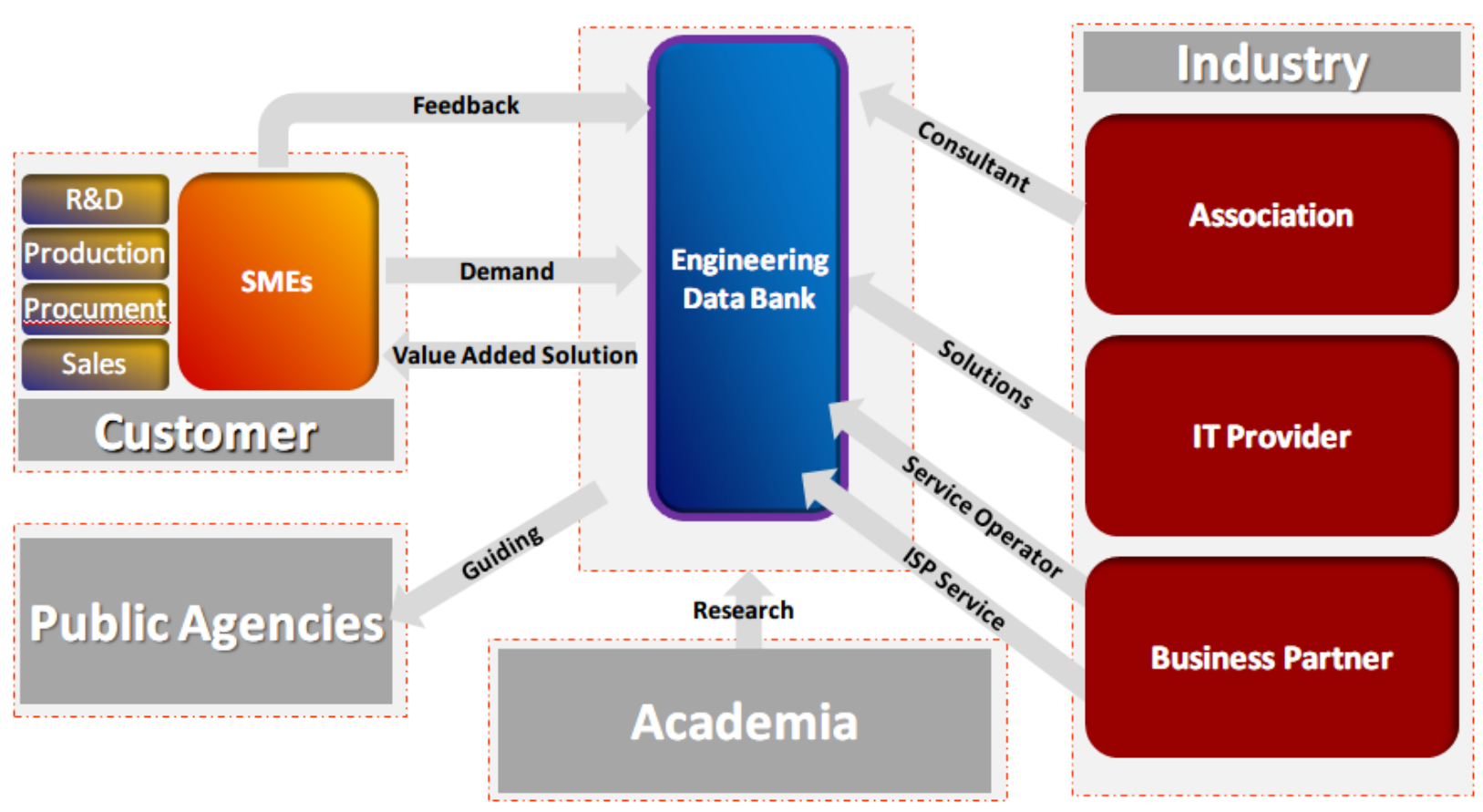

Figure 7. Ecosystem architecture of Engineering Data Bank. 


\section{Special Interest Group}

Innovative services were promoted in the precision machinery industry by providing training and simplifying entry barriers. Forums were held on topics such as trends in cloud technology in order to help the industry understand the technology, to reduce the industry's resistance to this new technology, and to increase the industry's interest in thinking about ways cloud technology can help it respond to the challenges of the future. A Special Interest Group (SIG) was established to allow industry representatives to exchange views and to build consensus. The SIG helped industry representatives to define the needs of the industry and to establish the parameters for service design, so as to ensure that the service design included all the features required to meet the needs which the group had defined. During this process 200 functions originally identified by the project team were aggregated into 80 functions in the first year, and then further concentrated into 10 functions in the second year. Cloud computing systems were created to enhance these features. In fact the SaaS service on the cloud showed that it has the versatility to serve an even broader customer base.

\section{Satisfactory localized service}

This project focused on interacting with customers. "The Precision Machinery Industry and Innovative Smart Living Service Center " was jointly established with the Precision Machinery Development Association at the Taichung World Trade Center as the first-tier service base in the Taichung area. A specialist is located in the Center to provide localized service, respond promptly to demands and to solve problems. The number of companies involved in this project has increased from 85 manufacturers in the first year to more than 400 manufacturers in the second year, reaching the operational scale of a Proof of Business (POB) for verification and is planning to form a startup company to provide services to business. The project is now being reviewed to see if it can become a commercial operation, and to work out what the charges for its services should be. Many potential paying users of the service when it is operated commercially in the future have been attracted because of its outstanding customer service. $80 \%$ of those using the service report themselves satisfied.

\section{International Recognition}

Due to its experience in implementing the site planning and operation of the i-Park, the project team was invited to serve as consultants in the Taichung Smart City project. They worked cooperatively on the development of a roadmap to make Taichung into a smart city by integrating ICT-enabled smart living services into the greater Taichung area. These services included the creation of the Intelligent Park cluster (the iPark), Intelligent Monitoring and Energy Saving services (iEN), and Intelligent Traffic Monitoring and Vehicle Tracking Services. As a result of this project Taichung City was the only Asian city selected to be a TOP7 award winner in the 2012 Intelligent Community Forum (ICF) Awards competition.

\section{Result and Discussion}

After the Engineering Data Bank was deployed to SMEs in the precision machinery industry, various kinds of data were collected and analyzed. The findings can be described as follows:

1. The user type distribution of the service is shown in Figure 8. , and it was found that the service was most used by R\&D, manufacturing, and sales departments, (68\% of users.)

2. The top 10 functions used are listed in Table 2

3. The service satisfaction by the users is show in Table 3.

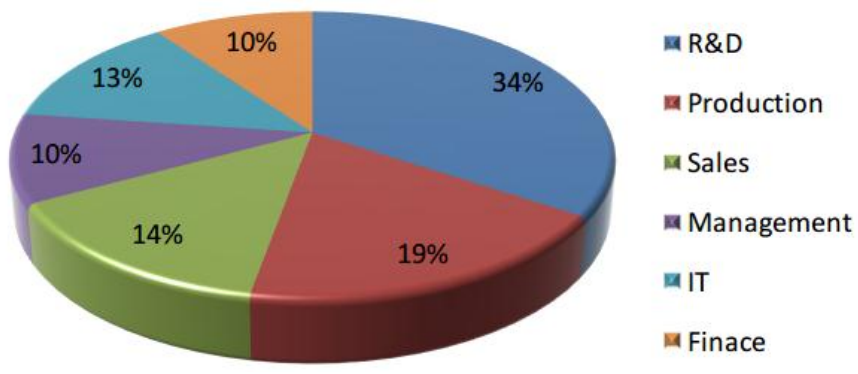

Figure 8. User Type Distribution.

Table 2. Top 10 Functions Used.

\begin{tabular}{|l|l|l|l|}
\hline & Function & & Function \\
\hline 1 & Drawing/Document Uploading & 6 & Press "good" \\
\hline 2 & Collaborative Edit and Locking & 7 & Document Discussion \\
\hline 3 & Drawing/Document Downloading & 8 & Document Delete \\
\hline 4 & Collaborative Design and Electronic Drawing Sign-up & 9 & Establishing Collaborative Working Subdirectory \\
\hline 5 & Design and Drawing Transmission & 10 & Establishing Collaborative Project \\
\hline
\end{tabular}


Table 3. Service satisfaction

\begin{tabular}{|l|l|l|l|l|l|}
\hline \multirow{2}{*}{ Department } & \multirow{2}{*}{$\begin{array}{l}\text { Enhanced } \\
\text { Efficiency }\end{array}$} & \multirow{2}{*}{ Satisfaction } & \multicolumn{2}{l|}{ Expected Rent } \\
\cline { 4 - 6 } & & & $1 \sim 1000$ & $1001 \sim 2000$ & $2001 \sim 3000$ \\
\hline R\&D & $91 \%$ & $83 \%$ & $50 \%$ & $50 \%$ & $0 \%$ \\
\hline Sales & $100 \%$ & $100 \%$ & $100 \%$ & $0 \%$ & $0 \%$ \\
\hline Production & $100 \%$ & $100 \%$ & $100 \%$ & $0 \%$ & $0 \%$ \\
\hline Management & $50 \%$ & $25 \%$ & $75 \%$ & $25 \%$ & $0 \%$ \\
\hline Others & $50 \%$ & $67 \%$ & $63 \%$ & $25 \%$ & $12 \%$ \\
\hline & $76 \%$ & $75 \%$ & $66 \%$ & $31 \%$ & $3 \%$ \\
\hline
\end{tabular}

After the service was employed for a period of time, several companies was interviewed about the benefits provided by the service, and it was found that

1. The accuracy of information transmission is greatly enhanced.

2. The optimal improvement of the operation process efficiency is about $18 \%$.

3. The labor cost saved is about 1-2 R\&D personnel.

4. This service can be integrated with the ISO process to enhance R\&D efficiency.

\section{Conclusion}

The adoption of the Living Lab Concept for developing a service cannot guarantee the success of the service, but can indeed increase the possibility of success. The ecosystem established for the service, systematic planning and implementation of the service, the systems developed for the service, and the team members who execute the project are all indispensable elements for the success of the service developed for the site. Our greatest experiential learning in this project was how to obtain a good balance between these elements to ensure the successful development of an innovative service.

\section{References}

[1] C. B. Wang, Present status of local machinery industry, 2011. [Online].

Available:

http://www.cnfi.org.tw/kmportal/front/bin/ptdeta il.phtml?Part=magazine10005-494-9

[2] "Strategic Review Board meeting of the Executive Yuan: ICT value added strategy in machinery industry," Industrial Development Bureau, Ministry of Economic Affairs, Taiwan, 2008.

[3] "Project report of value-added ICT application for traditional manufacturing industries," Industrial Development Bureau, Ministry of Economic Affairs, Taiwan, 2010.

[4] S. H. Liu, Y. H. Li, Y. C. Huang, and L. R. Yeh, 2010 machinery industry yearbook. HsinChu, Taiwan: Industrial Economics and Knowledge Center, Industrial Technology Research Institute, 2010.

[5] S. H. Liu, Y. H. Li, Y. C. Huang, and L. R. Yeh, 2011 machinery industry yearbook. HsinChu, Taiwan: Industrial Economics and Knowledge Center, Industrial Technology Research Institute, 2011.

[6] Living lab, Wikipedia. [Online]. Available: http://en.wikipedia.org/wiki/Living lab 